\title{
The Impacts of Ergonomic Aspects on the Quality
}

\author{
Reza Khani Jazani, Sajad Mousavi* \\ School of Health, Safety and Environment, Shahid Beheshti University of Medical Sciences, Teheran, I.R. Iran \\ Email: sajadmousavi19@gmail.com
}

Received 4 November 2013; revised 4 December 2013; accepted 7 January 2014

Copyright (C) 2014 by authors and Scientific Research Publishing Inc.

This work is licensed under the Creative Commons Attribution International License (CC BY). http://creativecommons.org/licenses/by/4.0/

(c) (i) Open Access

\begin{abstract}
In recent times, the relationship between quality and ergonomics discipline is a challenging topic. Although there are similarities and differences between these two areas, it is not so easy to describe the connection between these two issues. In this study by surveying several articles, different areas of ergonomics are divided into five categories including hardware ergonomics, environmental ergonomics, software ergonomics, work design ergonomics and macro ergonomics, then the impact on the quality of each of these areas will be discussed. Finally, the article concludes that, to reach an acceptable quality considering the ergonomic principles is an integral component of the organization policy.
\end{abstract}

\section{Keywords}

Ergonomics; Quality; Organization; Productivity

\section{Introduction}

Each issue of ergonomics and quality has their own discipline. There are many similarities between the two, although there are many differences with each other. Ergonomics and the quality of both the history and the issues are new [1]. Relationships between ergonomics and quality in recent years have been taken into account. Therefore, there is little information in this area [2]. There is not enough information about how various aspects of ergonomic can have an influence on quality. Clarifying the relationship between the two issues is not only helpful for managers who focus more on quality but also for ergonomists who are trying to show their ability. In this article, we have tried to collect detailed information about the relationship between ergonomics and quality and have outlined them. So firstly, brief definitions of ergonomics and quality will be given, then, the literature on how the relationship between the two applies was reviewed. Finally, it was concluded that ergonomists must do

\footnotetext{
${ }^{*}$ Corresponding author.
} 
more research on quality to be able to convince management for considering ergonomic principles as an integral component of organization policy to improve quality and productivity.

\section{Literature Review}

The Nordic Ergonomics Society defines ergonomics as the 'Interdisciplinary field of science and application considering integrated knowledge of human requirements and needs in the interaction human-technology-environment in the design of technical components and work systems' [2]. This definition has a key role to atone people which customers and employees are included. Due to this, ergonomics and quality can be considered according to their core concepts and general approaches. Both the ergonomics and quality can be described by man as the core of the work systems [3]. Quality has been defined as 'fitness for use [4]. In a more elaborate meaning,' The quality of a product or service is its ability to satisfy the needs and expectations of the customers [5]. Personnel in an industrial environment are known as internal customers and the end-user considered as external customers. Naturally, all customers have needs and expectations regarding their interaction with products, which also include ergonomics aspects on the product they use. These needs and expectation fulfill the definitions of both ergonomics and quality, thereby confirming the overlap of the definitions [1].

After clarifying definitions, the various aspects of ergonomics is given. Then, the impact on the quality of each of them, is discussed. Different aspects of ergonomics based on Henrick book are stated [6]. Mr. Henrick defined the ergonomics as a human-system interference technology. This technology has at least five clearly identifiable subparts. These are as follows:

1. Human-machine interface technology or hardware ergonomics

2. Human-environment interface technology or environmental ergonomics

3. Human-software interface technology or cognitive ergonomic

4. Human-job interface technology or work design ergonomics

5. Human-organization interface technology or macro ergonomics

The article goes on to examine the impact on the quality of each of the aforementioned aspects.

\subsection{The Relationship between Hardware Ergonomics and Quality}

Human-machine interface technology or hardware ergonomics. This primarily concerns the study of human physical and perceptual characteristics and the application of these data to the design of controls, displays, seating, workstations and related workspace arrangements [7].

A study of the wood industry in South Africa was conducted in 1994 among 300 foresters in the industry due to inappropriate Leg protectors. An average of ten injuries per day was occurring with an average sick leave of five days per injury. The ergonomic redesign of the instrument (leg protector) showed that no injury or damage has occurred during the day for the foresters and this design lead to annual savings of $\$ 4$ million in the company [8].

In another study in which the Microsoft conducted in 2004, showed that the use of ergonomic tools through the use of computers has led to a 10 percent reduction in injuries from repetitive movements (RSI) In the amount of $\$ 700,000$ in annual savings [9]. In addition, LEE conducted a study in 2001 at a Korean electric appliance company, which focused on machinery and tools, which were used by workers. At first stage ergonomic risk assessment was done then using simple and low cost ergonomic methods resulted in increased productivity $10 \%$ - 30\%)and cost savings (approximately \$17.01 million). Further, the number of musculoskeletal problems was significantly reduced [3]. The following (Figure 1) shows hardware ergonomics intervention.

According to the above researches, we can conclude on how hardware ergonomics can have a tremendous impact on the quality.

\subsection{The Relationship between Ergonomics and Environmental Quality}

Human-environment interface technology or environmental ergonomics. It concerns the effects of various physical environmental factors, such as illumination, heat, cold, noise and vibration, on human performance, and the application of these data to the design of physical environments for people [7].

In a number of papers Sanders and McCormick on the effects of noise, vibration and light on human error and bad performance did some research [10]. 


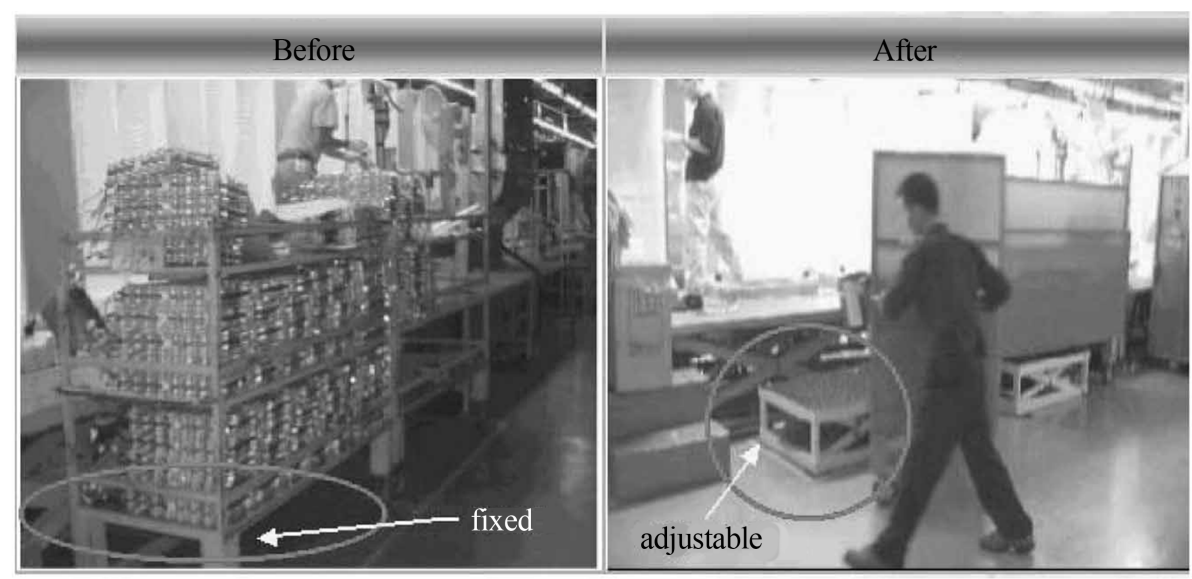

Figure 1. A lifter for a container.

In another study Griffin, vibrations at frequencies above than $20 \mathrm{~Hz}$, shown that these vibrations can lead to neurological-muscle disorders and will eventually lead to human errors [11].

Chemicals can cause different effects on performance, for example, organic solvents may lead to changes in the central nervous system which results in the disruption of individual decisions and activities. That was showed by Stollery [12].

According to the above studies, it is clear that the lack of attention to environment ergonomic can impact on employee performance and, ultimately, leads to a decline in the quality, this is shown graphically by Eklund [1]. As follows (Figure 2).

\subsection{The Relationship between Cognitive Ergonomics and Quality}

Human-software interface technology, which is the central focus of cognitive ergonomics. It deals with the way people think, conceptualize, and process information, and the application of these data to software design [7].

Several studies that have done by Wagenaar, Larson and Wallace Showed that cognitive failure have a large impact on job performance and safety [13]-[15]. In another study, Treat and colleagues concluded that more than 70 percent of accidents are due to human errors [16]. Given that Mr. Allahyari have expressed in his article that cognitive errors can be used as an indicator of information processing capability, which can affect on the performance and activities [17]. So what can be concluded is, the impact of cognitive ergonomics on the quality is obvious.

In another research project in which an Ameritech company was done in America, they redesigned the CRT displays used in the company according to the principles of cognitive ergonomics (the way people think, conceptualize, and process information).the results showed a 600-ms reduction in average call operating time. This reduction in time will lead to savings of \$2.94 million annually [18]. The following (Figure 3) shows CRT before and after the changes.

\subsection{The Relationship between Work Design Ergonomics and Quality}

Human-job interface technology or work design ergonomics. It concerns the design of jobs to ensure proper workload and characteristics such as task variety or having different meaningful things to do in one's work, identity or sense of job wholeness, significance or perceived job meaningfulness, autonomy or control over one's work, and feedback or knowledge of results [7].

In a study conducted in wood industry in South African, redesigning the Tractor-trailer workstation will result in improved visibility and comfort of operator. The extent of the damage to machine components dropped. This changes in the workstation eventually lead to annual savings \$ 65,000 [8]. In another study on the Handling \& Stock Keeping system, the company redesigned a workstation ergonomically. The redesign reduced the noise level in the area from $96 \mathrm{db}$ to $78 \mathrm{db}$, increased production by $10 \%$, dropped rejection from $2.5 \%$ to $1 \%$, and paid back the redesign and development costs in approximately 18 months [8].

At the end of this section, another study is discussed which was done by Choobineh and colleagues in Iranian 


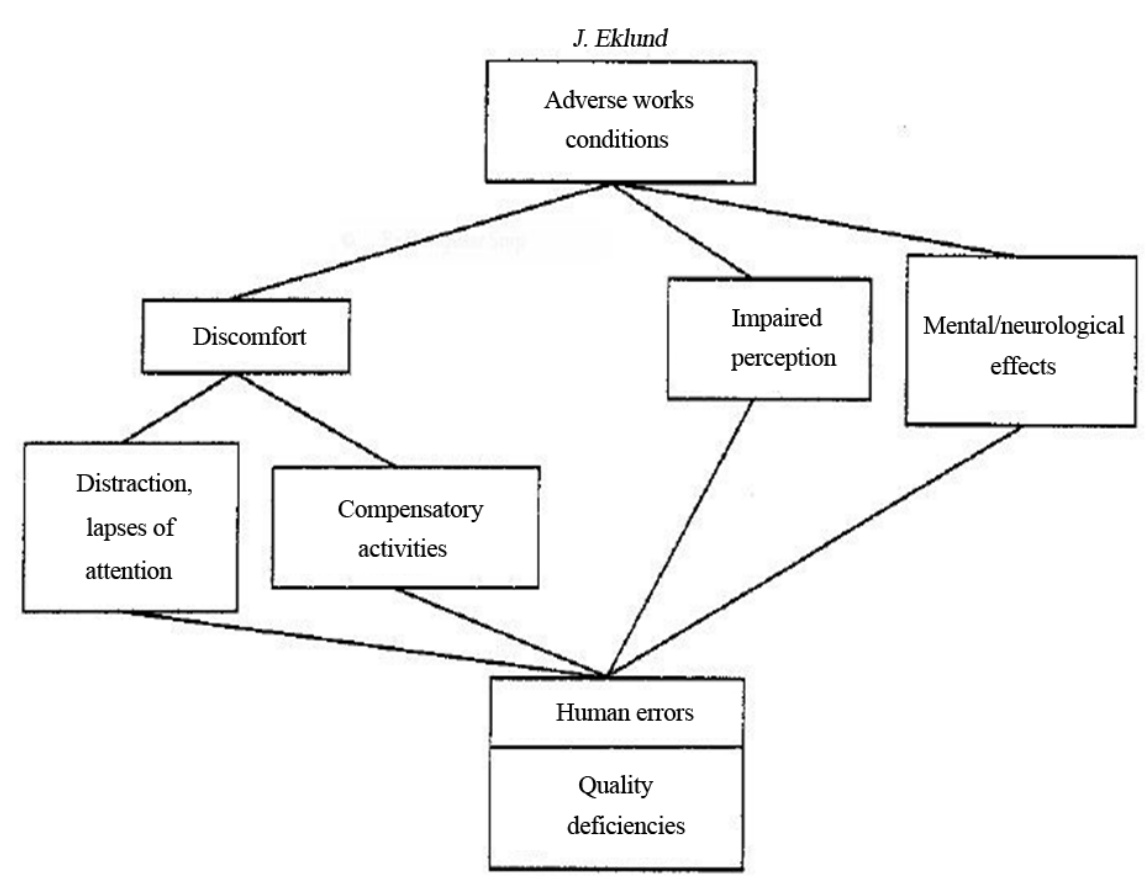

Figure 2. A summary of some of the principal identified relationships between physical work conditions and quality deficiencies.
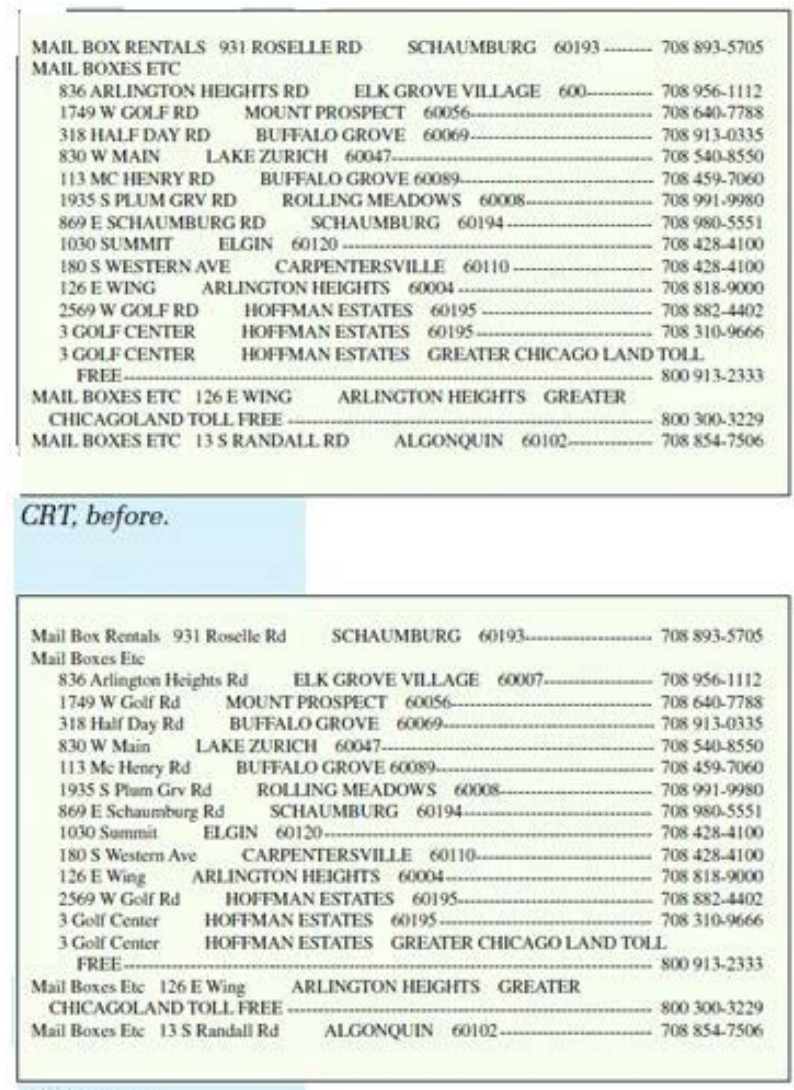

CRT, after.

Figure 3. CRT Redesign. 
Hand-Woven carpet Industry about workstation design. 1439 randomly selected weavers participated in this study. The results showed that prevalence rates of musculoskeletal disorders were high. Finally, a review of the decision was taken to redesign their workstation. After making changes, weavers were questioned on this point, 70 percent said they are very pleased with the new conditions and have better comfort during work with better quality [19]. Before (Figures 4 and 5) and after images of the workstation is shown.

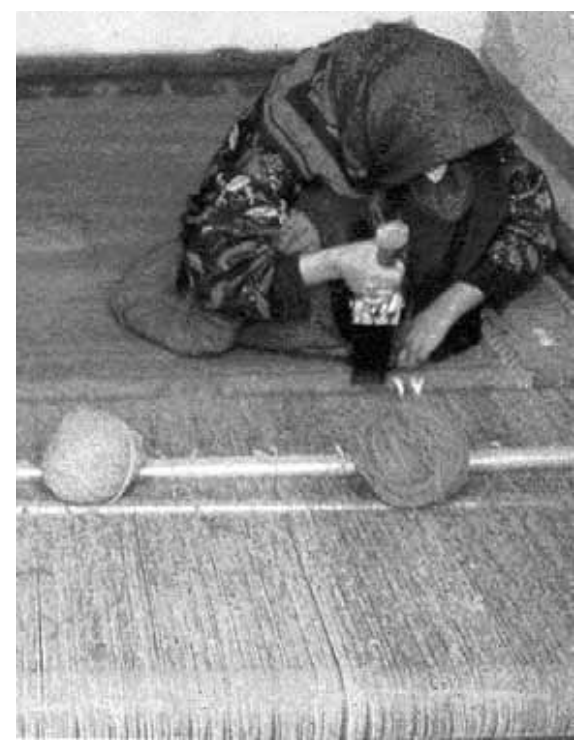

Figure 4. Work station before design. A woman is working at horizontal loom. The back is bent excessively; her knees are folded and the overall body posture dramatically deviates from the neutral.

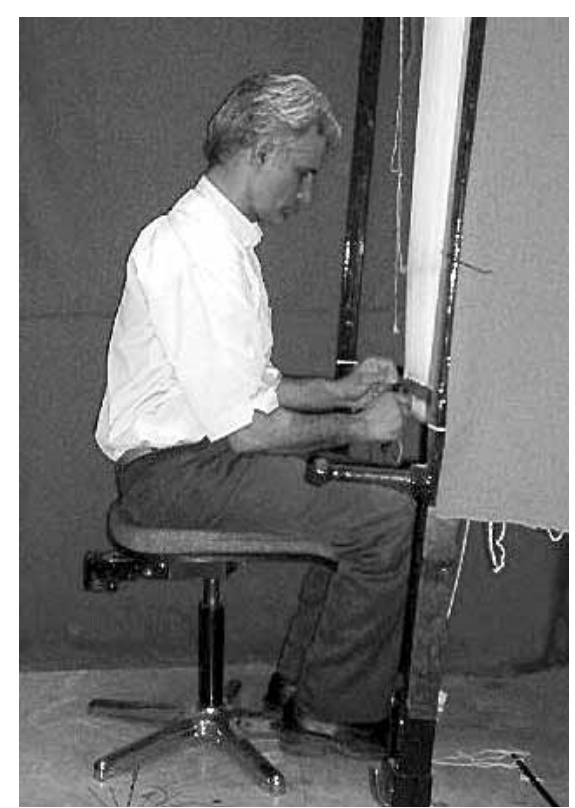

Figure 5. Workstation after redesign. A prototype of the designed loom and workstation. Legs are well supported. there is enough clearance under the loom for legs. The overall body posture is neutral. 


\subsection{The Relationship between Macro Ergonomics and Quality}

Human-organization interface technology or macro ergonomics. It concerns the interfacing of employees with the over-all organizational design of the work system so as to most effectively utilize both the personnel and technology employed in the system in responding to the organization's external environment [7].

Henrick proposed a macro ergonomics model that could be applied to the prevention of occupational injuries [20]. In another paper Henrick has spoken about importance of the macro ergonomics and its impact on productivity [21]. Is determined according to both studies, how macro ergonomics impact on the quality of the work.

In another study Keliner showed, Macro ergonomics has been demonstrated to improve work system performance throughout sub-system areas, including productivity, quality, safety and health, quality of work life, user satisfaction, etc. [22].

Another study was conducted by Habibi and colleagues, macro ergonomic conditions and its relationship with job satisfaction of employees in a company were analyzed. After reviewing the results of the statistical analysis, showed that there is a direct relationship between job satisfaction and general aspects of macro ergonomics. $(\mathrm{r}=$ 0.638 and Pvalue $=0.001$ ) [23]. At the end of this section, Roonay and colleagues study is also discussed. The study was done in L.L. Bean Company, known internationally for the high quality of its clothing products. They have reported on the use of macro ergonomics as an approach and methodology for introducing total quality management (TQM). In two years of study and using macroergonomics methods, the accident rate dropped 70\% as well as significantly increased levels of job satisfaction [24].

Above studies showed how easily, the macro ergonomics principles could affect the quality of work.

\section{Conclusion}

It is clear that the issue of quality is not achieved only by improving processes and products, so the people will be involved in this process, which can result in desirable quality. Since the issue of ergonomics is based on knowledge of needs and expectations of human, so by designing work systems according to ergonomics principals, we can get a desirable quality not only for employees as a internal customer but also for customer as a external customer. In this study, we have examined different areas of ergonomic research on their impact on the quality; it is important to show how the ergonomic aspects influence improvement of job satisfaction, safety and health, work conditions and organization productivity and ultimately improve the quality. Finally, it is suggested according to this issue that information about the relationship between ergonomics and quality is rare, further research in this area is necessary to be done by ergonomists to convince manager that, for achieving desirable quality considering ergonomic principal is vital for organizations.

\section{References}

[1] Eklund, J. (1997) Ergonomics, Quality and Continuous Improvement Conceptual and Empirical Relationships in an Industrial Context. Applied Ergonomics, 40, 982-1001. http://dx.doi.org/10.1080/001401397187559

[2] Eklund, J. (2001) A Developmental Quality Approach for Ergonomics. Proceeding of the SELF-ACE Conference on Ergonomics for Changing Work, 1, 26-38.

[3] Lee, K.S. (2005) Ergonomics It Total Quality Management: How Can We Sell Ergonomics to Management? Applied Ergonomics, 48, 577-558.

[4] Juran, J.M. (1974) Quality Control Handbook. McGraw- Hill, New York.

[5] Bergman, B. and Klefsjo, B. (1994) Quality: From Customer Needs to Customer Satisfaction. Student Litterateur, Lund.

[6] Henrick, H.W. and Keleiner, B. M. (2002) Macro Ergonomics, Theory, Methods and Applications. Mahwah, London.

[7] Hendrick, H.W. and Kleiner, B.M. (2001) Macroergonomics: An Introduction to Work System Design. Human Factors and Ergonomics Society, Santa Monica.

[8] Warkotsch, W. (1994) Ergonomic research in South African Forestry. Suid-Afrikaanse Bosboutydskrif, 171, 53-62.

[9] Microsoft Corporation (2004) Microsoft Tablet PC—Visual Design Guidelines (Microsoft Tablet PC). http://www.scribd.com/doc/145286021/Occupational-Ergonomics-Handbook

[10] Sanaders, M. S. and Mccormick, E. J. (1993) Human Factors in Engineering and Design. 7th Edition, McGraw-Hill, New York.

[11] Griffin, M. J. (1992) Vibration. In: Smith, A. and Jones, D., Eds., Handbook of Human Performance, Academic Press, San Diego, 55-78. 
[12] Stollery, B. (1992) Organic Solvents, In: Smith, A. and Jones, D. Eds., Handbook of Human Performance, Academic Press, San Diego, 211-236.

[13] Larson, G.E., Alderton, D.L., Neideffer, M. and Underhill, E. (1997) Further Evidence on Dimensionality and Correlates of Cognitive Failure Questionnaire. British Journal of Psychology, 88, 29-38. http://dx.doi.org/10.1111/j.2044-8295.1997.tb02618.x

[14] Wallace, J.C. and Chen, G. (2005) Development and Validation of a Work-Specific Measure of Cognitive Failure: Implications for Occupational Safety. Journal of Occupational \& Organizational Psychology, 78, 615-632. http://dx.doi.org/10.1348/096317905X37442

[15] Wagenaar, W.A., Hudson, P.T.W. and Reason, J.T. (1990) Cognitive failures and accidents. Applied Cognitive Psychology, 4, 273-294. http://dx.doi.org/10.1002/acp.2350040405

[16] Treat, J. R. (1980) A Study of Research Factors Involved in Traffic Accidents. The HSRI Research Review, University of Michigan Highway Safety Research Institute.

[17] Allahyari, T., Seraji, G., Iravani, M., Hosseini, M., Adl, J., Younesian, M. and Kass, S.J. (2008) Cognitive Failure, Driving Error and Driving Accidents. International Journal of Occupational Safety and Ergonomics, 14, 149-158.

[18] Hendrick, H.W. (1996) Good Ergonomics Is Good Economics. Human Factors and Ergonomics Society, Santa Monica.

[19] Choobineh, A., Lahmi, M., Shahnavaz, H., Jazani, R.Kh. and Hosseini, M. (2004) Musculoskeletal Symptoms as Related to Ergonomic Factors in Iranian Hand-Woven Carpet Industry and General Guidelines for Workstation Design. International Journal of Occupational Safety and Ergonomics, 10, 157-168.

[20] Hendrick, H.W. (1986) Macroergonomics: A Conceptual Model for Integrating Human Factors with Organizational Design. In: Brown Jr., O. and Hendrick, H.W., Eds., Human Factors in Organizational Design and Management, North-Holland, Amsterdam, 467-478.

[21] Henrick, H.W. (1992) A Macroergonomic Approach to Work Organization for Improved Safety and Productivity, In: Kumar, S., Ed., Advances in Industrial Ergonomics and Safety IV, Taylor \&Francis, London, 3-10.

[22] Keliner, B.M. (2001) Macroergonomics. In: Karwowski, W., Eds., International Encyclopedia of Ergonomics and Human Factors, Taylor \& Francis, London, 124-125.

[23] Habibi, E., Amini, N.R., Porabdian, S., Rismanchian, M. and Hasanzadeh, A. (2008) Assessment of Relationship between Macro Ergonomic Conditions and Employees Work Satisfaction Touse-eh and Omran Factory. Iran Occupational Health Journal, 5, 15-20.

[24] Rooney, E.F., Morency, R.R. and Herrick, D.R. (1993) Macroergonomics and Total Quality Management at L. L. Bean: A Case Study. In: Neilson, N.R. and Jorgensen, K., Eds., Advances in Industrial Ergonomics and Safety V, Taylor \& Francis, London, 493-498. 